Review

\title{
Critical Barriers in Software Outsourcing Vendor Organizations and Their Impacts on Software Outsourcing Clients: A Systematic Literature Review
}

\author{
${ }^{1}$ Ismail Keshta and ${ }^{2}$ Ammar Odeh \\ ${ }^{1}$ Department of Computer Science and Information Systems, AlMaarefa University, Riyadh, Saudi Arabia \\ ${ }^{2}$ Department of Computer Science, Princess Sumaya University for Technology Amman, Jordan
}

\author{
Article history \\ Received: 17-07-2020 \\ Revised: 03-10-2020 \\ Accepted: 05-10-2020 \\ Corresponding Author: \\ Ammar Odeh \\ Department of Computer \\ Science, Princess Sumaya \\ University for Technology \\ Amman, Jordan \\ Email: a.odeh@psut.edu.jo
}

\begin{abstract}
Globalization and technological advancement have driven up the demand for software as many enterprises seek to gain a competitive edge through efficient business operations. Whereas software provides this capacity, the resources involved in software development sometimes provide a stumbling block, especially for startups and smaller businesses. Software development outsourcing or offshore software development offers a viable alternative for these enterprises. Software development outsourcing is a contractual agreement between a client and vendor organization (s), who then provide part or all of the software development related services at an agreed fee paid by the client. Despite the apparent importance of offshore software development, there is limited research literature that explores the general practices in software development outsourcing. Besides, identifying barriers that often present a significant challenge for client organizations has received a little interest from researchers. This paper presents a Systematic Literature Review (SLR) of 68 research articles to identify the critical barriers for offshore software development outsourcing vendors. In order to increase the internal validity of the reported findings, the articles selected for the review were taken from three continents; Africa, Asia and Europe. The critical barriers established from the study included communication problems, cultural barriers and incompatibility with the client's requirements. From the findings, it is recommended that vendors address these barriers for an improved relationship between themselves and the clients. Moreover, addressing these barriers offer the vendors with an opportunity to position themselves strategically within the offshore outsourcing industry. Furthermore, the findings provide meaningful literature in the continuum of Software Development Outsourcing for Software project managers, researchers and other participants in the field. More importantly, the presented literature offers a starting point for generalizing the reported findings within the context of Software Development Outsourcing.
\end{abstract}

Keywords: Offshore Software Development, Outsourcing Vendors, Systematic Literature Review

\section{Introduction}

Technological advancement and innovation is fast changing the activities in the global market. There is high demand in the production of specialized software in the telecommunications industry and this has meant that there is need for outsourcing from the global market (Khan et al., 2011; Calefato et al., 2016). Software outsourcing involves a contractual agreement between two parties in which they are involved in developing, planning, maintaining and managing software service's operations. Enterprises have evolved and focused on cost saving initiatives in the decision-making process on software development has been based on the cost-saving strategies (Yousif, 2015). Emphasis has been placed on improving the overall performance of organization with the decision-makers implementing strategies that can improve organizational capabilities, efficiency and productivity (Colomo-Palacios et al., 2014). Strategic software outsourcing has been the key strategy in 
software development process that should be explored (Khan and Khan, 2017; Ali et al., 2020a). With the focus of most organizations being on software outsourcing, industries have restructured in reducing cost of production and researchers have increased their attention on the decision-making process on software outsourcing.

Based on the existing organization's practices, industrial organizations have focused on reducing their costs by outsourcing software development activities (Betz et al., 2014; Ali et al., 2019). The procedures that are used in the development and implementation of software are expensive and it requires considerable a lot of time for implementing it. Software development outsourcing is facing one challenge, which is on handling complexity associated with coordination issues especially on time differences and cultural perspectives (Vrhovec et al., 2015). For the cultural misfit, organizations are concerned with the style of working as different organizations have different working styles that are essential in meeting its mission and vision (Nie and Hammouda, 2017) statement. The other challenge includes unrealistic expectations and miscommunication amongst the employees in the industry. Some of the companies have adopted software outsourcing development strategies in optimizing the intention of company to improve its software process. It is argued that offshoring can add value to the business as quality software is outsourced (Skowronski and Benton Jr., 2018).

Knowledge transfer is an important issue when considering the success of implementing offshore software outsourcing, but this is often neglected by some of the organizations (Betz et al., 2014). When compared to co-located and in-house projects, offshore outsourcing is faced with high level of complexity. Also, there is the problem of language barrier as the cultural differences and infrastructural development can have an impact on the knowledge transfer, which can ultimately affect the success level of the project (Dettmer 2014; Ghobadi and Mathiassen, 2016).

Despite the importance of offshore software development outsourcing, little research has been performed on offshore software development outsourcing practices in general and identification of barriers that have a major impact on client organisations in particular. To do this we intend to address the following research questions:

RQ1. What barriers within a software outsourcing vendor organizations have a negative impact on software outsourcing clients?

RQ2. Do the identified barriers vary from continent to continent?

The organization of this paper is given as: Section I (introduction), section II (background and motivation of doing this research), section III (research methodology, section IV (findings), section V (limitations) and section VI (conclusion and future work).

\section{Background and Motivation}

Numerous researchers have emphasized on the importance of Offshore Software Development Outsourcing (OSDO). One key aspect that has been outlined is on the relationship existing between the vendors and the clients can either result to success or failure in the outsourcing arrangements made. In achieving maximum benefits amongst the outsourcing companies, necessity is placed on the positive relationship between the vendor and the client (Nie and Hammouda, 2017). Different researchers have outlined the maintaining elastic vendor and client relationship and this has created business values when outsourcing software (Abbas and Dart, 1998; Betz and Mäkiö, 2008). In understanding the distinct relationship in the outsourcing process has meant that proper arrangements have been made and issues of dependency have been achieved. For the software industry, outsourcing practices have been essential in improving operationalizing the agreement developed. The nature of outsourcing within the industry is significantly evolving and it is currently based on the formal contracts developed amongst the organization (Ali and Khan, 2014; Ali et al., 2020b; Shafiq et al., 2019). As such, it has positively impacted the success in the software development and improves the quality of software development (Seth et al., 2015).

Concerning the recently conducted research regarding OSDO, there are gaps in the study (from 2010 and later), some of the theories highlighted below are from these research findings. In the case of the factors that have influenced offshore outsourcing, the main problem provided by (Liu and Yuliani, 2016) is funding of internal development of software. Other researchers including (Wong et al., 2010) identified problems with organizational performances and high costs reported in the financial statement. In expounding further on organizational performance issues, the authors indicated that the organizations involved reported reduction in earnings, high leverage costs, high debt and poor information technology infrastructure. As such, they are the main determinants for the organization to largely invest in OSDO. Kranz et al. (2016) research findings pointed out on the cost expectations associated with the internal development of software as most of the organizations have faced increased competition and they are willing to reduce costs where possible. Also, the authors indicated the time period taken to complete the development of software program, technical issues and quality of the software program as the other hindrances causing offshoring software development outsourcing. Strategic decision on OSDO was also influenced by the size of the organizations; although, this remains to be debatable (Jain et al., 2011). The argument is that smallsized organizations can easily outsource software 
development unlike big companies where it has all the necessary resources to develop their software programs.

The link between the OSDO and organizational performance was also another theoretical perspective that was assessed by various authors. Khan and Khan noted that industrial organizations are interested in using software developed for strategic purposes for the organization (Khan and Khan, 2017). Strategic exploitation of the economy is an important aspect when they are pursuing their strategic goals within the region. Global exploitation of the OSDO resources have meant that such organizations should strategize on the best way in which they can implement policies that will report positive trend in the policies implemented. From (Ang and Inkpen, 2008) study, the problem that most of the organizations face in the implementation of OSDO program is on the accessibility of the suppliers for the software, interaction costs being high and poor quality information technologies that are used. Such organizations are striving to restructure its business initiatives and manage the complexity in the contractual agreements developed. The standard that is developed in the organization is on linking the microeconomic issues with the internal resources for the entity. As such, they are interested in acquiring capabilities that can be difficult to assess when outsourcing operations from offshore companies.

The work in this systematic review complements the previous work done by the past researchers. It provides an insight into the modern challenges (between 2010 to now) that have been reported in affecting the implementation of OSDO amongst the organizations. Most of the organizations have managed the challenges associated with offshore software development outsourcing and this has meant that it they have benefited from reduced cost of developing software. However, there is little empirical research that has been conducted in determining the selection process and the outsourcing of the offshore software development. With a clear understanding of the barriers developed, it will be instrumental in managing the outsourcing process as the organization will be well-prepared to deal with these challenges reported in the organization. There is no proper documentation on the extensive nature of these barriers; as such, the information generated from this research will be informative to the practitioners willing to outsource offshore software development processes.

In this study, an exploratory study is provided with the focus being on identifying the critical barriers to the offshore software development outsourcing vendors. This will be integral in determining the negative impact that such barriers can have when outsourcing software development clients. Clear information on the barriers that affect the success of the offshore software development outsourcing will help the clients to address them and compete globally.

\section{Research Methodology}

This study used Systematic Literature Review (SLR) process as its main approach in collecting data. Considering that the topic selected has been subjected to constant research and different findings are reported annually, sometimes the findings reported can be conflicting. With the use of systematic literature review, high quality research contents will be identified, critically evaluated and integrated in improving the quality of the research findings. With the use of systematic literature review, the intention was on determining the extent to which the existing research study has progressed in clarifying the problem of OSDO. Also, it SLR was used in identifying the relationships, contradictions existing, gaps and any inconsistencies in the past literature and it was essential in exploring reasons for such inconsistency. General statements are formulated with the use of SLR and they are essential in providing an overarching conceptualization of the ideas generated by the different researchers. Finally, SLR is essential in developing and evaluating relevant theory and providing the researcher with directions for conducting future research on the topic. As such, the use of systematic literature review was essential in adding knowledge to the existing research conducted on the topic of study.

In this research methodology section, a systematic review protocol was conducted with the intention of describing in detail this report. The main steps that were used in constructing search items are given below:

- $\quad$ Determine the search strategy and perform search for the relevant studies

- $\quad$ Perform the study selection process

- Apply study quality assessment

- Extract data and analyse the extracted data

The details for these four steps are provided in the following sections.

\section{A. Determine Search Strategy and Perform Search}

In determining the suitable and relevant search terms, research questions developed were categorized in terms of population, intervention and the outcomes. This was critical in constructing reliable search terms for this research.

\section{Population}

Based on the research question developed, the main population for this study is the software outsourcing vendors and software outsourcing clients.

\section{Intervention}

Critical barriers that are faced by the software outsourcing vendors and clients. 


\section{Outcome}

Negative implication of the software outsourcing to the reputation of the vendors and the impact on the trust that the clients have towards the software outsourcing vendors.

As this is mainly an exploratory study, the papers that are reviewed are the empirical studies, case studies, theoretical studies and experts' opinions.

In the first research question which is on "what barriers within a software outsourcing vendor organizations have a negative impact on software outsourcing clients?", an example of search terms include:

- Population - software outsourcing clients

- Intervention - what barriers

- Outcome - negative impact

As different studies are aimed at being collected, experimental research will be inclusive of all the other types of research conducted and this will not be used as a discriminatory factor in searching for the research studies.

A search string was developed using the Boolean operators with trial search conducted using the following: ("software outsourcing" OR "IT outsourcing" OR "IS/IT") AND ("vendor" OR "selection criteria" OR "readiness" OR "client" OR "factors" OR "barriers" OR "models").

From the information that was retrieved, the search strings that were used are given as:

Search string 1:

("software outsourcing" OR "information systems outsourcing" OR "information technology outsourcing" OR "IS outsourcing")

AND

(barriers OR barrier OR obstacles OR hurdles OR risks $O R$ "risk analysis" OR "critical factors")

Search string 2:

("software outsourcing" OR "information systems outsourcing")

AND

("selection process" OR "selection criteria" OR "recruitment procedure" OR choosing OR methodology $O R$ "analyzing vendor's capability" OR assessment $O R$ "evaluation process" OR agreement OR contracting $O R$ alliance OR co-ordination OR "outsourcing relationship")

Search string 3:

("software outsourcing" OR "information systems outsourcing" OR "information technology outsourcing" OR "IS outsourcing")

AND

("selection process" $O R$ "selection criteria" $O R$ "recruitment procedure" OR choosing OR methodology OR "analyzing vendor's capability" OR assessment OR "evaluation process" OR agreement OR contracting $O R$ alliance OR co-ordination OR "outsourcing relationship")
Search string 4:

("software outsourcing" OR "information systems outsourcing" OR "information technology outsourcing" $O R$ "IS outsourcing")

AND

(vendor $O R$ vendors $O R$ service-provider $O R$ dealer $O R$ trader OR marketer OR seller OR developer)

Search string 5:

(CBIS outsourcing" OR "computer-based information systems outsourcing" $O R$ "software facility management" OR "software contracting-out")

AND

(Clients OR client OR outsourcer OR buyer OR customer OR purchaser OR user OR consumer OR shopper)

Search string 6:

("software outsourcing" OR "information systems outsourcing" OR "information technology outsourcing" OR "IS outsourcing" OR "IT outsourcing" OR "CBIS outsourcing" OR "computer-based information systems outsourcing" OR "software facility management" OR "software contracting-out")

AND

(Undermine OR damage OR challenge OR challenges $O R$ risk) $O R$ ("negative impact" $O R$ "relationship failure" $O R$ "poor results" OR dissatisfaction OR disappointment OR displeasure OR disagreement OR "bad effect" OR "lack of trust" OR unconfident OR rejection $O R$ "uncertain decision" OR conflict OR uncertainties).

\section{B. Study Selection Process}

The inclusion and exclusion criteria used in selecting the information are given below.

\section{Inclusion Criteria}

In determining the publications and articles that were to be included in the current study, the following criteria were used:

- Studies that described the capabilities of vendors towards software outsourcing

- Studies describing barriers to effective offshore software development outsourcing for both the clients and vendors

- Studies providing relationship between the software vendors and clients when outsourcing offshore software development

- Studies describing factors that demotivate clients and vendors from software outsourcing 
Table 1: Data sources

\begin{tabular}{lccc}
\hline Resource & Total results found & Primary selection & Final selection \\
\hline Google Scholar & 136 & 28 & 16 \\
IEEExplore & 122 & 42 & 12 \\
Science Direct & 102 & 54 & 14 \\
CiteSeer & 89 & 36 & 18 \\
ACM & 32 & 16 & 8 \\
Total & 480 & 176 & 68 \\
\hline
\end{tabular}

\section{Exclusion Criteria}

Some of the studies and publications were not included on this study and the exclusion criteria that were used include:

- Studies that were not addressing the two research questions

- Studies that were not describing the capabilities of vendors on software outsourcing

- Studies that were not describing barriers to effective offshore software development outsourcing for both the clients and vendors

- Studies that did not provide the relationship between the software vendors and clients when outsourcing offshore software development

\section{Selection Process}

In selecting the articles to be used, reading of the title of the article was necessary. After the title has been ascertained to be addressing the research topic, the abstract is also read and this will be followed by reading the entire article. The selection process was undertaken by the primary researcher and this was essential in reducing bias. There were 176 papers (Table 1), after the primary selection process was completed.

\section{Study Quality Assessment}

In the final selection process, quality assessment of the papers retrieved was performed. The quality assessment was undertaken at the time of extracting these papers. The reviewers asked key questions on determining the quality of the papers including:

- From the article, is the offshore software outsourcing vendors properly screened?

- Are the barriers critically addressed in the articles extracted?

Each of these factors are marked as 'YES', 'NO' or 'NA", but the results in determining quality of the articles were not used to limit the articles retrieved.

\section{Data Extraction and Analysis}

The review was undertaken by a single researcher, who was alone responsible for the data extraction. A secondary reviewer was approached for guidance in case of an issue regarding the data extraction.
The inter-rater reliability test was performed after the data extraction process by the primary reviewer. The secondary reviewer has selected 5 publications randomly from the list of publication already chosen by the primary reviewer. The secondary reviewer has independently extracted the data from the randomly selected publication.

The results were compared with the results produced by the primary reviewer and no differences were found.

From each paper we extracted a list of Quotes, where each Quote described a list of barriers that have a negative impact on software outsourcing clients in the selection process of offshore software development outsourcing vendors.

The following data was extracted from each publication: Date of review, Title, Authors, Reference, Database, Critical Barriers, Methodology (interview, case study, report, survey etc.), Target Population, Sample Population, Publication Quality Description, Organization Type (software house, university, research institute etc), Company size (small, medium, large), Country/location of the Analysis and Year.

\section{Findings}

\section{A. RQ1 - Barriers Identified using SLR}

In answering the first research question, the barriers identified are provided in Table 2.

Poor quality of service offered by the vendor companies was reported by $57 \%$ of the total studies. Gupta (2017) study reviewed the role of the quality control measures in influencing the decision to select the outsourcing software development vendor. The study recommended that for the companies to realize the value of their investments, they should avoid the payment of lump-sum amounts to companies that have not fully provided their performance track record. Software development process involves high level of uncertainty and quality can be compromised while making payment to a project that has not been fully reviewed.

Poor infrastructure as a factor that affects the outsourcing of software was supported by $62 \%$ of the publications selected. Goby (2015) claims that entrepreneurs tend to ignore the importance that is placed on the infrastructural development especially on the protection of the intellectual property. Startling results have demonstrated that the infrastructural 
development is largely linked with the wage that is offered to the employees and economic incentives that are implemented. Paradoxical nature of the software projects that are developed has meant that weak infrastructural development has impaired the outsourcing of the software in the region.

Strategic inflexibility was a barrier that was supported by $18 \%$ of the publications. Srikanth and Puranam (2014) conducted an interview on 32 project managers from 60 projects that were conducted on offshore software industry. The projects were based on two main dimensions, which were the spatial distribution and multiple/single firms' delivery of the software outsourcing. The aim of this study was on ascertaining the role played by the organization especially in strategic flexibility of its activities. The evidence suggested that the success of the software outsourcing project was mainly aligned to the coordination mechanisms that are developed by such entities. For the distributed projects, it was evident that they relied extensively on the strategic flexibility of the management's activities especially where there are constant changes in the activities of the company.

Communication problem was also cited in $50 \%$ of the primary publications reviewed as an important aspect that influences the success of the software outsourcing initiatives. Jain et al. (2011) publication assessed the problem with remaining silent especially on the issues related to the project being developed. This empirical study conducted reviewed the prior research, which suggested that there is no communication between the client managers and the vendor's employees and this can lead to poor quality services that are offered to clients (Goby, 2015; Hossain et al., 2009; Odeh et al., 2020). Cross-cultural teams are also facing the challenge of understanding the views and demands of the employees and this can sometimes result to conflict in the decision-making process. For the cultural barrier, this barrier was supported by $62 \%$ of the publications and it shows the importance that should be placed on cultural adaptation in improving the quality of software developed. Cultural adaptation and vendor silence are the major problems that should be addressed in ensuring that the offshore outsourcing is undertaken with minimal problem.

Technical capability issues were highlighted in $46 \%$ of the publications with the argument being that lack of proper mechanism in addressing the challenge of technicalities when developing software. Qu et al. (2011) study drew knowledge from extensive research and theoretical foundations in underpinning the concept of technical capabilities and addressing its impact in software development outsourcing. The major industries that were reviewed included those that were characterized by high level of dynamism, munificence and capital intensity. It was evident that the technical capabilities of the different companies had an implication on the effectiveness of the software development process.
Table 2: Barriers

\begin{tabular}{lll}
\hline Barriers & $\begin{array}{l}\text { Freq. } \\
(\mathrm{n}=68)\end{array}$ & $\%$ \\
\hline Communication problem & 34 & 50 \\
Cultural barrier & 42 & 62 \\
Country instability & 28 & 41 \\
Technical capability issues & 31 & 46 \\
Hidden costs & 30 & 44 \\
Delays in delivery & 28 & 41 \\
Lack of control over the project & 18 & 26 \\
Incompatibility with client's requirements & 51 & 75 \\
Poor infrastructure & 42 & 62 \\
Opportunistic behavior & 28 & 41 \\
Strategic inflexibility & 12 & 18 \\
Lack of project management & 19 & 28 \\
Poor quality of service offered & 39 & 57 \\
\hline
\end{tabular}

Furthermore, the study findings suggested that timely strategic actions that are developed are aimed at maximizing the resources available and this will be achieved by having reliable project management team. This was supported by $28 \%$ of the publications conducted. Given that the organizations are evolving, industries have focused on flexible strategies and policy framework and it is the organization that understands the significance of having a flexible regime that can realize success in the industry. However, on a different note, a study conducted by (Vrhovec et al., 2015) explained that industry concentration has an implication on the software outsourcing measures that can be influential in achieving the effectiveness in the software development. Organizations that are concentrated industries can be influential in improving the institutional pressures and this can be influential in affecting the cost-driven initiatives.

Hidden cost barrier was also supported by $44 \%$ of the publications and this has meant that the client's firms have avoided the vendor companies due to the increased costs. The budgeted costs that are incurred by the organization influence their decision-making process on the software infrastructure to be developed. Anderson Jr. et al. (2019) study findings relied on the data collected from the Compustat and U.S. Bureau of Economic analysis in determining the cost implication of the offshore software development. The empirical study validated the hypothesis that there were hidden costs that were charged to the clients and this had an impact on the demand for the software developed. The findings suggested that the IT service providers and business executives should be concerned with transparency when quoting the prices or costs of the software developed. It demonstrated the managerial insights that should be used in addressing complexities and dynamics that are involved when outsourcing software. 
Table 3: Barriers across different continents

\begin{tabular}{|c|c|c|c|c|c|c|}
\hline \multirow[b]{3}{*}{ Barriers } & \multicolumn{6}{|c|}{ Sample size find through SLR $(\mathrm{N}=68)$} \\
\hline & \multicolumn{2}{|c|}{ Africa $(n=15)$} & \multicolumn{2}{|c|}{ Asia $(n=34)$} & \multicolumn{2}{|c|}{ Europe $(\mathrm{n}=19)$} \\
\hline & Freq. & $\%$ & Freq. & $\%$ & Freq. & $\%$ \\
\hline Communication problem & 14 & 93 & 24 & 71 & 8 & $42 \%$ \\
\hline Cultural barrier & 12 & 80 & 21 & 62 & 4 & $21 \%$ \\
\hline Country instability & 8 & 53 & 17 & 50 & 5 & $26 \%$ \\
\hline Technical capability issues & 3 & 20 & 20 & 59 & 0 & $0 \%$ \\
\hline Hidden costs & 7 & 47 & 27 & 79 & 0 & $0 \%$ \\
\hline Delays in delivery & 4 & 27 & 26 & 76 & 11 & $58 \%$ \\
\hline Lack of control over the project & 0 & 0 & 12 & 35 & 12 & $63 \%$ \\
\hline Incompatibility with client's requirements & 15 & 100 & 10 & 29 & 9 & $47 \%$ \\
\hline Poor infrastructure & 10 & 67 & 7 & 21 & 3 & $16 \%$ \\
\hline Opportunistic behaviour & 2 & 13 & 9 & 26 & 0 & $0 \%$ \\
\hline Strategic inflexibility & 3 & 20 & 8 & 24 & 1 & $5 \%$ \\
\hline Lack of project management & 4 & 27 & 12 & 35 & 0 & $0 \%$ \\
\hline Poor quality of service offered & 2 & 13 & 0 & 0 & 1 & $5 \%$ \\
\hline
\end{tabular}

\section{B. RQ2-Do these Barriers Vary Across Different Continents?}

In answering this research question, the time limit meant that publications were from only three continentsAfrica, Asia and Europe. As illustrated in Table 3, the publications shows that in Africa continent there 15 publications selected, Asia (34 publications) and Europe (19 publications). Majority of the publications were from Asia and this had implications on the findings of the study as it aligned mainly on the views of the Asian individuals.

From the findings in Table 3, communication problem $(93,71$ and 42\%), cultural barriers (80, 62 and $21 \%$ ) and incompatibility with client's requirements (100, 29 and 47\%) were the popular barriers that were reported in the publications made in the three continents. Notably, in African continent, communication problem was the main barrier and this meant that there were countries in which they did not understand the language that is communicated. Incompatibility with the client's requirements had a close and direct relationship with the communication problem. Where there is lack of communication amongst the population, it is difficult to convey correct and accurate information to the relevant parties.

Cultural barrier was also a barrier in Africa with eighty-percent of the publications collected from this region showing that culture played a distinct role. Some of the publications outlined the challenge of having diverse views regarding the culture prevailing in other continents. Also, other barriers that impacted the effectiveness of the offshore software outsourcing in Africa were the hidden costs $(47 \%)$, country instability $(53 \%)$, poor infrastructure $(67 \%)$ and lack of project management initiatives $(27 \%)$. With these in place, it was evident that the challenges that the Africa continent vendors and clients were facing were based on the governance and the perception of the individuals in an attempt in improving the effectiveness of the operations.

In the case of Asia, there were 34 publications that were collected from the search databases conducted. The findings suggested that most of the papers that were collected were aligned to the hidden costs (79\%), communication problem $(71 \%)$, delays in delivery $(76 \%)$ and cultural barrier (62\%). These barriers had an implication on the overall development of the offshore software development. Other factors that affected the offshore software development outsourcing include technical capability, country instability and lack of project management. All these had an implication on the effectiveness of the project development and implications of the outsourcing strategies developed.

In European continent, lack of control over the project is considered to be the main barrier $(63 \%)$ and this is followed by delays in delivery of the software developed at $58 \%$. There is also the barrier of incompatibility with client's requirements (47\%) and communication problem (42\%), which has an implication on the overall demand for the offshore software development outsourcing. Although there are other barriers to the development of software, these were considered to be the major factors that the vendors and clients should review towards implementing measures that will necessitate effectiveness in the long-run.

\section{Limitations}

With the use of SLR in addressing the research question, there are limitations that should be addressed in necessitating effectiveness of the process. First, there is the challenge of validity of the data collected as the articles are often complex and does not have specific barrier that they are addressing. In screening the abstracts of the extracted publications, human errors 
including discrepancies and inconsistencies can have an implication on the validity and reliability of the findings. As such, this can affect the credibility of the information presented.

Moreover, while the 68 articles presented a valid sample size for the literature review, most of the studies were published by academicians, who did not necessarily have experience in software outsourcing. In response to this threat, a plan is underway to conduct an empirical study in the software outsourcing industry to validate the findings presented here and establish any possible features that might have been missed in this study.

Since there are many articles in software outsourcing, there is an obvious possibility that several relevant articles might have been left out in this SLR. However, like in other SLR, this was not a systematic omission. Besides, the sample was as diverse as possible with articles from three continents; Africa, Asia and Europe.

In the study, articles that adopted random sampling of software-developing outsourcing vendors were omitted from the review. However, the research questions for the SLR provided for the most comprehensive investigation on the topic. Generalization of the findings is validated through cross-examination with related studies, which showed considerable similarities.

In the selection of primary sources and data extraction, the inter-rater reliability test was conducted to limit the researcher's bias. Nonetheless, not every paper could be checked by a secondary reviewer. Though the limited resources made it impossible to exhaustively use all the available digital libraries, the ones that were used proved enough to generalize the findings of the study, which were validated through cross-examination with related articles.

\section{Conclusion and Future Work}

The findings of this study show that the major barriers that cut across all the three continents are the communication problem, cultural barriers and incompatibility with client's requirements. Offshore software development outsourcing is always conducted in regions that are characterized by enough personnel and it is the duty of the vendors and client's organizations to address these problems by using the available personnel.

Research on the cultural values and norms prevailing in the region should be conducted and the client's requirements need to be followed to the latter. Future work should be done independently on these three barriers and offer coherent information on the challenges that face the three continents.

\section{Acknowledgement}

The authors would like to acknowledge the support provided by Princess Sumaya University for Technology while conducting this research work.

\section{Author's Contributions}

All authors equally contributed in this work.

\section{Ethics}

This article is the original contribution of the author and is not published elsewhere. There is no ethical issue involved in this article

\section{References}

Abbas, R., \& Dart, P. (1998). Outsourcing Software Applications Development: Issues, Implications and Impact. In 6th European Conference on Information Systems (ECIS'98), Aix-enProvence.

Ali, S., \& Khan, S. (2014). Software outsourcing partnership model. International symposium on research in innovation and sustainability, 26(4), 1437-1442.

Ali, S., Li, H., Khan, S. U., Abrar, M. F., \& Zhao, Y. (2020a). Practitioner's view of barriers to software outsourcing partnership formation: An empirical exploration. Journal of Software: Evolution and Process, 32(5), e2233.

Ali, S., Huang, J., Khan, S. U., \& Li, H. (2020b). A framework for modelling structural association amongst barriers to software outsourcing partnership formation: An interpretive structural modelling approach. Journal of Software: Evolution and Process, 32(6), e2243.

Ali, S., Ullah, N., Abrar, M. F., Majeed, M. F., Umar, M. A., \& Huang, J. (2019). Barriers to software outsourcing partnership formation: an exploratory analysis. IEEE Access, 7, 164556-164594.

Anderson Jr., E. G., Jiang, X., Parker, G. G., \& Tan, B. (2019). Systems integration and the dynamics of partial outsourcing. Production and Operations Management, 28(2), 319-340.

Ang, S., \& Inkpen, A. C. (2008). Cultural intelligence and offshore outsourcing success: A framework of firm-level intercultural capability. Decision Sciences, 39(3), 337-358.

Betz, S., \& Mäkiö, J. (2008). Applying the OUTSHORE approach for risk minimisation in offshore outsourcing of Software Development projects. In Multikonferenz Wirtschaftsinformatik (pp. 1101-1112).

Betz, S., Oberweis, A., \& Stephan, R. (2014). Knowledge transfer in offshore outsourcing software development projects: An analysis of the challenges and solutions from German clients. Expert Systems, 31(3), 282-297.

Calefato, F., Lanubile, F., Conte, T., \& Prikladnicki, R. (2016). Assessing the impact of real-time machine translation on multilingual meetings in global software projects. Empirical Software Engineering, 21(3), 1002-1034. 
Colomo-Palacios, R., Casado-Lumbreras, C., SotoAcosta, P., García-Peñalvo, F. J., \& Tovar, E. (2014). Project managers in global software development teams: a study of the effects on productivity and performance. Software Quality Journal, 22(1), 3-19.

Dettmer, B. (2014). International service transactions: Is time a trade barrier in a connected world?. International Economic Journal, 28(2), 225-254.

Ghobadi, S., \& Mathiassen, L. (2016). Perceived barriers to effective knowledge sharing in agile software teams. Information systems journal, 26(2), 95-125.

Goby, V. P. (2015). Financialization and outsourcing in a different guise: the ethical chaos of workforce localization in the United Arab Emirates. Journal of Business Ethics, 131(2), 415-421.

Gupta, R. S. (2017). Knowledge Management and Quality Control in Software Outsourcing Projects. International Journal of Knowledge Management (IJKM), 13(4), 31-55.

Hossain, E., Babar, M. A., \& Paik, H. Y. (2009, July). Using scrum in global software development: a systematic literature review. In 2009 Fourth IEEE International Conference on Global Software Engineering (pp. 175-184). Ieee.

Jain, R. P., Simon, J. C., \& Poston, R. S. (2011). Mitigating vendor silence in offshore outsourcing: An empirical investigation. Journal of Management Information Systems, 27(4), 261-298.

Khan, S. U., \& Khan, A. W. (2017). Critical challenges in managing offshore software development outsourcing contract from vendors' perspectives. IET software, 11(1), 1-11.

Khan, S. U., Niazi, M., \& Ahmad, R. (2011). Barriers in the selection of offshore software development outsourcing vendors: An exploratory study using a systematic literature review. Information and Software Technology, 53(7), 693-706.

Kranz, J. J., Hanelt, A., \& Kolbe, L. M. (2016). Understanding the influence of absorptive capacity and ambidexterity on the process of business model change-the case of on-premise and cloud-computing software. Information Systems Journal, 26(5), 477-517.

Liu, J. Y. C., \& Yuliani, A. R. (2016). Differences between clients' and vendors' perceptions of IT outsourcing risks: Project partnering as the mitigation approach. Project Management Journal, 47(1), 45-58.
Nie, E., \& Hammouda, I. (2017, May). An exploratory study on strategic software development outsourcing. In 2017 IEEE 12th International Conference on Global Software Engineering (ICGSE) (pp. 106-115). IEEE.

Odeh, A., Alarbi, A., Keshta, I., \& AbdelFattah, E. (2020). "Efficent Predication of phishing Website Using Multilayer perceptron (MLP)." Journal of Theoretical and Applied Information Technology 98, no. 16 (2020).

Qu, W. G., Pinsoneault, A., \& Oh, W. (2011). Influence of industry characteristics on information technology outsourcing. Journal of Management Information Systems, 27(4), 99-128.

Seth, F. P., Mustonen-Ollila, E., Taipale, O., \& Smolander, K. (2015). Software quality construction in 11 companies: an empirical study using the grounded theory. Software Quality Journal, 23(4), 627-660.

Shafiq, M., Zhang, Q., \& Akbar, M. A. (2019, December). Software requirements engineering maturity model (SREMM) in offshore software development outsourcing. In 2019 International Conference on Frontiers of Information Technology (FIT) (pp. 101-1013). IEEE.

Skowronski, K., \& Benton Jr., W. C. (2018). The influence of intellectual property rights on poaching in manufacturing outsourcing. Production and Operations Management, 27(3), 531-552.

Srikanth, K., \& Puranam, P. (2014). The firm as a coordination system: Evidence from software services offshoring. Organization Science, 25(4), 1253-1271.

Vrhovec, S. L., Trkman, M., Kumer, A., Krisper, M., \& Vavpotič, D. (2015). Outsourcing as an economic development tool in transition economies: Scattered global software development. Information technology for development, 21(3), 445-459.

Wong, A., Tjosvold, D., \& Chen, N. Y. F. (2010). Managing outsourcing to develop business: Goal interdependence for sharing effective business practices in China. Human Relations, 63(10), $1563-1586$.

Yousif, M. (2015). A study of software development outsourcing in Sudan. SUST Repository. 374, 74-98. 